The use of telescopes with internal focussing for stadia surveying

This content has been downloaded from IOPscience. Please scroll down to see the full text. 1920 Trans. Opt. Soc. 2220

(http://iopscience.iop.org/1475-4878/22/1/304)

View the table of contents for this issue, or go to the journal homepage for more

Download details:

IP Address: 202.195.128.45

This content was downloaded on 02/10/2015 at 07:02

Please note that terms and conditions apply. 


\title{
THE USE OF TELESCOPES WITH INTERNAL FOCUSSING FOR STADIA SURVEYING
}

\author{
By Major E. O. HENRICI, R.E.
}

MS. received, 25th October, 1920. Read and discussed, i ith November, 1920.

TelesCOPEs with an internal negative focussing lens, with cross hairs rigidly fixed in the tube carrying the object glass, have been introduced of late years for use with surveying instruments. Such telescopes have several advantages; they can be made dust and damp tight, or even water tight, and the collimation is less liable to variation during focussing. When an ordinary draw tube is used for the focussing it is difficult to make and keep the movement absolutely true so that the cross hairs remain on the optical axis of the object glass when the tube is moved. With the internal focussing lens the cross hairs do not move, and not only can the moving part (viz. the negative lens) be more easily guided, so that its excentric movement is small, but also a given excentric movement has much less displacing effect on the image, relative to the cross hairs, than an equal movement of the cross hairs themselves. This point has been dealt with in the Zeitschrift für Instrumentenkunde for 1909 , p. 329 .

Such a telescope is equivalent to one having an object glass of varying focal length, and the angle subtended by the stadia hairs in the diaphragm will vary according to the focal length, i.e. according to the distance of the object on which the telescope is focussed. In the ordinary telescope $L=k l+f+c$, where $L$ is the distance from the vertical axis of the instrument to the stadia rod, $l$ the intercept on the rod between the stadia hairs, $f$ the focal length of the object glass, $c$ the distance of the object glass in front of the vertical axis, and $k$ a constant. In the case under consideration neither $k$ nor $f$ are constants, and it may be of interest to investigate the practical effect of this in stadia working.

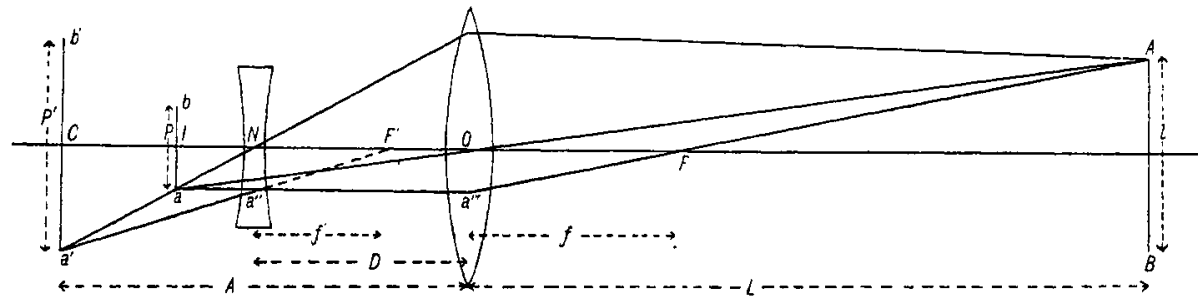

In the figure $A B$ (length $l$ ) is the portion of the stadia rod viewed between the cross hairs $a^{\prime} b^{\prime}$. $O$ is the object glass with focal length $f$ and first focal point at $F$, and $N$ is a negative lens with focal length $f^{\prime}$ and first focal point at $F^{\prime} . A$ is the fixed 
distance between the cross hairs $a^{\prime} b^{\prime}$ and the object glass $O, L$ the distance from the staff to the object glass, and $D$ the distance between the lenses when an image of $A B$ is formed at $a^{\prime} b^{\prime}$.

If the lens $N$ were not present an image of $A B$ would be formed at $a b$ (length of image $p$ ), distant $f_{2}$ behind the object glass, and a ray from $A$ passing through $F$ would take the path $A F a^{\prime \prime \prime} a^{\prime \prime} a$, the portion $a^{\prime \prime \prime} a$ being parallel to the axis, hence

$$
\frac{A B}{a b}=\frac{L-f}{f}, \text { or } L=\frac{f l}{a b}+f=\underset{p}{f l}+f=k l+f,
$$

where $k$ is a constant; this is the ordinary formula for stadia work. With the negative lens in position the ray $A F a^{\prime \prime \prime} a^{\prime \prime}$ will be refracted at $a^{\prime \prime}$ to $a^{\prime}$ where $F^{\prime \prime} a^{\prime \prime} a^{\prime}$ is a straight line, hence

$$
\frac{p^{\prime}}{p}=\frac{C F^{\prime}}{N F^{\prime}}=\frac{f^{\prime}+A-D}{f^{\prime}} \text { and } L=\frac{f\left(f^{\prime}+A-D\right)}{f^{\prime} p^{\prime}} l+f .
$$

Here $A, f$, and $f^{\prime}$ are constants, but $D$ increases as $L$ diminishes.

Let $D=D_{\infty}+d$ where $D_{\infty}$ is the value of $D$ when the telescope is at stellar focus; $D_{\infty}$ is then a constant, and

$$
L=k l-\frac{f l d}{f^{\prime} \ddot{p}^{\prime}}+f, \text { where } k=\frac{f\left(f^{\prime}+A-D_{\infty}\right)}{f^{\prime} p^{\prime}}
$$

It remains to find how the second term varies as $L$ varies. If we simply say that for practical purposes $L=k l$, then strictly the distance $L$ is not measured from the object glass but from a point distant $E=f-\frac{f l d}{f^{\prime} p^{\prime}}$ in front of the object glass. The problem resolves itself into finding the values of $E$ corresponding to various values of $L$. To express $E$ in terms of $L$ leads to a rather complicated formula, but it is comparatively simple to express both $E$ and $L$ in terms of $d$. From the figure

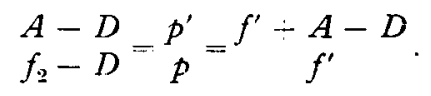

Hence $\quad f_{2}=\frac{-D^{2}+D A+f^{\prime} A}{f^{\prime}+A-D}$, also $L=\frac{f f_{2}}{f_{2}-f}$.

Put $D_{\infty}=n A(n<I)$, then $D=n A+d$, from which

$$
f=\frac{A^{2} n(\mathrm{I}-n)+f^{\prime} A}{f^{\prime}+A(\mathrm{I}-n)}, \text { or } f^{\prime}=\frac{A(\mathrm{I}-n)(f-n A)}{A-f}
$$

Also

$$
f^{\prime}+A-D_{\infty}=\frac{A^{2}(\mathrm{I}-n)^{2}}{A-f} .
$$

Hence $\quad f_{2}=\frac{-d^{2}(A-f)+A d(\mathrm{I}-2 n)(A-f)+A^{2}(\mathrm{I}-n)^{2}}{A^{2}(\mathrm{I}-n)^{2}-d(A-f)}$,

and

$$
L=f \cdot \frac{-d^{2}(A-f)+A d(\mathrm{r}-2 n)(A-f)+A^{2}(\mathrm{r}-n)^{2} f}{-d^{2}(A-f)+d\left\{A^{2}(\mathrm{r}-2 n)+f(2 n A-f)\right\}} .
$$


From (I)

hence

$$
k l\left(\mathbf{1}-\frac{d}{f^{\prime}+A-D_{\infty}}\right)=L-f
$$

$$
k l=\frac{(L-f) A^{2}(\mathrm{I}-n)^{2}}{A^{2}(\mathrm{I}-n)^{2}-d(A-f)}=\frac{f^{2} A^{2}(\mathrm{I}-n)^{2}}{-d^{2}(A-f)+d\left\{A^{2}(\mathrm{I}-2 n)+f(2 n A-f)\right\}},
$$

and

$$
E=L-k l=\frac{f\{A(\mathrm{I}-2 n)-d\}}{A(\mathrm{I}-2 n)+f-d} .
$$

If $n=\frac{1}{2}$, as indicated in Zeiss' British patent No. 25622 of 19ro, then $E$ reduces to $\frac{-f d}{f-d}$, which is zero when the telescope is at stellar focus. If $n<\frac{1}{2}, E$ is positive, i.e. the apex of the tacheometric angle, or the point from which $L$ is measured, is thrown forward, but if $n>\frac{1}{2}, E$ becomes negative and the apex is thrown back towards the eyepiece. Table I shows the values of $E$ and $f^{\prime}$ when $A=$ I for various values of $n$, and for $f=\cdot 80, \cdot 85$ and $\cdot 90$. Table II shows the values of $d, L$ and $E$ for three telescopes for which (I) $f={ }^{\circ} 9, n=\cdot_{4}, f^{\prime}=3 \cdot 0,(2) f={ }^{9}, n=\cdot 5, f^{\prime}=2 \cdot 0$, and (3) $f=\cdot 9, n=\cdot 6, f^{\prime}=\mathrm{I} \cdot 2$, all distances being measured in terms of the length (A) of the telescope. Table III gives corresponding values for similar telescopes, except that $f=\cdot 8$. For mechanical reasons it is inconvenient to have $D$ greater than $.75 A$, and the values greater than this have been shown in italics.

If $R$ is the distance from the centre of the instrument to the staff, and $c$ the distance from the centre of the instrument to the object glass, then $R=k l+c+E$. It will be seen from the tables that $c+E$ decreases for any given range as $n$ increases, but that its variation with range for a given telescope increases as $n$ increases. The use of a short focus negative lens (high value for $n$ ) in order to reduce the absolute value of $c+E$ will introduce complications into the optical corrections of the lens system, and impair the optical properties of the telescope.

With a 12-inch telescope which follows the Zeiss patent $\left(n=\frac{1}{2}\right), E$ varies from $O$ at long ranges to about $-\cdot r \mathrm{ft}$. at $28 \mathrm{ft}$. and $-\cdot 25 \mathrm{ft}$. at $15 \mathrm{ft}$. The vertical axis of the instrument will be about 6 inches behind the object glass, so that if we simply take the range from the instrument as $k l$ the error will vary from about 6 inches at long ranges to 5 inches at $30 \mathrm{ft}$. and 3 inches at $15 \mathrm{ft}$. In view of the fact that such short ranges will seldom be measured, and that at long ranges the errors of reading the staff will be greater than 6 inches, the error in assuming that the telescope is anallatic is generally negligible. If a shorter telescope be used the errors will be smaller. It must be remembered that in plotting detail an error of a foot in the distance measured is in most cases of no consequence, as it cannot be plotted except on very large scales. In running traverses short sights will seldom be taken and with long sights the error is smaller than that due to reading the staff. If a closer approximation is required it will in almost all cases suffice to add a constant equal to the distance between the axis of the instrument and the object glass, and the residual error will not exceed 2 or 3 inches at any distance. If this is of importance (it can only be of importance where great accuracy is required at very short ranges) the distances corresponding to the various stadia readings should be tested and tabulated for each instrument in use, but it is very seldom that this will be worth while. 
Table I. Values of $E$ and $f^{\prime}$ for $A=\mathbf{I}$.

\begin{tabular}{|c|c|c|c|c|c|c|}
\hline \multirow{2}{*}{$n$} & \multicolumn{2}{|c|}{$f=80$} & \multicolumn{2}{|c|}{$f=\cdot 85$} & \multicolumn{2}{|c|}{$f=-90$} \\
\hline & $E$ & $f^{\prime}$ & $E$ & $f^{\prime}$ & $E$ & $f^{\prime}$ \\
\hline $\begin{array}{l}.30 \\
.35 \\
.40 \\
.45 \\
.50 \\
.55 \\
.60 \\
.65 \\
.70\end{array}$ & $\begin{array}{l}+.267 \\
+.218 \\
+.160 \\
+.089 \\
\pm .000 \\
-.114 \\
-.266 \\
-.480 \\
-.800\end{array}$ & $\begin{array}{l}I \cdot 70 \\
I \cdot 46 \\
I \cdot 20 \\
\cdot 96 \\
\cdot 75 \\
\cdot 56 \\
.40 \\
.26 \\
\cdot 15\end{array}$ & $\begin{array}{l}+.272 \\
+.222 \\
+.162 \\
+.089 \\
\pm .000 \\
-.113 \\
-.262 \\
-.464 \\
-.755\end{array}$ & $\begin{array}{l}2 \cdot 57 \\
2 \cdot 17 \\
1 \cdot 80 \\
1 \cdot 47 \\
1 \cdot 33 \\
.90 \\
.67 \\
.47 \\
.30\end{array}$ & $\begin{array}{l}+\cdot 277 \\
+\cdot 225 \\
+\cdot 163 \\
+\cdot 090 \\
\pm \cdot 000 \\
-\cdot 112 \\
-\cdot 256 \\
-\cdot 450 \\
-\cdot 720\end{array}$ & $\begin{array}{r}4.20 \\
3.58 \\
3.00 \\
2.47 \\
2.00 \\
1.57 \\
1.20 \\
.88 \\
.60\end{array}$ \\
\hline
\end{tabular}

Table II. Values of $L$ and $E$ for $f={ }_{9}, A=\mathbf{I}$.

\begin{tabular}{|c|c|c|c|c|c|c|}
\hline \multirow{2}{*}{$d$} & \multicolumn{2}{|c|}{$n=\cdot 4, f^{\prime}=3.0$} & \multicolumn{2}{|c|}{$n=-5, f^{\prime}=2 \cdot 0$} & \multicolumn{2}{|c|}{$n=6, f^{\prime}=1 \cdot 2$} \\
\hline & $L$ & $E$ & $L$ & $E$ & $L$ & $E$ \\
\hline .000 & $\infty$ & +-163 & $\infty$ & $\pm \cdot \infty 00$ & $\infty$ & -.257 \\
\hline .005 & 531 & $+\cdot 160$ & 453 & -.005 & 370 & -.266 \\
\hline OI & 268 & $+\cdot 157$ & 228 & - OIO & 157 & $-\cdot 274$ \\
\hline .02 & 135 & $+\cdot 150$ & I 16 & -.020 & 95 & $-29 I$ \\
\hline .03 & $9 \mathrm{I}$ & $+\cdot 143$ & 79 & $-.03 I$ & 64 & -309 \\
\hline .04 & 69 & +.136 & 59 & -.042 & 49 & -327 \\
\hline .05 & 55.5 & $+\cdot 129$ & 48 & -.053 & 39.5 & -346 \\
\hline .06 & 47 & $+\cdot 12 I$ & 40 & -.064 & $33 \cdot 5$ & -365 \\
\hline .07 & 40.5 & +114 & 34 & -.076 & 29 & -386 \\
\hline .08 & 36 & $\begin{array}{l}+.106 \\
+\cdot 008\end{array}$ & $\begin{array}{l}31 \\
28\end{array}$ & $\begin{array}{l}-.088 \\
-.100\end{array}$ & $\begin{array}{l}26 \\
23\end{array}$ & $\begin{array}{l}-407 \\
-.428\end{array}$ \\
\hline $\begin{array}{l}.09 \\
.10\end{array}$ & $\begin{array}{l}32 \\
29\end{array}$ & $\begin{array}{l}+.098 \\
+.090\end{array}$ & $\begin{array}{l}28 \\
25 \cdot 5\end{array}$ & $\begin{array}{l}-\cdot 100 \\
-\cdot 112\end{array}$ & $\begin{array}{l}23 \\
21\end{array}$ & -.428 \\
\hline $\begin{array}{l}\text {. I0 } \\
\text { I } 5\end{array}$ & $\begin{array}{l}29 \\
20.5\end{array}$ & $\begin{array}{l}+.090 \\
+.047\end{array}$ & $\begin{array}{l}25^{\circ} \\
18\end{array}$ & -180 & 15 & $\begin{array}{l}-450 \\
-.572\end{array}$ \\
\hline $\begin{array}{l}15 \\
.20\end{array}$ & 16 & $\begin{array}{l}+.047 \\
\pm .000\end{array}$ & I 5 & -.257 & $1 \overrightarrow{2}$ & $\begin{array}{l}-572 \\
-.720\end{array}$ \\
\hline 25 & 14 & -.053 & 12 & -720 & & \\
\hline
\end{tabular}

Table III. Values of $L$ and $E$ for $f=8, A=1$.

\begin{tabular}{|c|c|c|c|c|c|c|}
\hline \multirow{2}{*}{$d$} & \multicolumn{2}{|c|}{$n=\cdot 4, f^{\prime}=\mathrm{I} \cdot 2$} & \multicolumn{2}{|c|}{$n=\cdot 5, f^{\prime}=\cdot 75$} & \multicolumn{2}{|c|}{$n=\cdot 6, f^{\prime}=\cdot 4$} \\
\hline & $L$ & $E$ & $L$ & $E$ & $L$ & $E$ \\
\hline .000 & $\infty$ & $+\cdot 160$ & $\infty$ & \pm .000 & $\infty$ & -267 \\
\hline .005 & $23 I$ & +157 & 200 & $=.005$ & 170 & -276 \\
\hline .01 & 116 & +153 & 100 & -.010 & 86.5 & $-\cdot \mathbf{2} \dot{8}_{4}$ \\
\hline .02 & 59 & $+\cdot 147$ & 52 & -.020 & 44 & -303 \\
\hline .03 & 40 & +140 & $33^{\circ} 5$ & -.031 & 29.5 & -.323 \\
\hline .04 & 30 & +133 & 26 & -.042 & $22 \cdot 5$ & -343 \\
\hline .05 & $24 \cdot 5$ & +126 & $2 I$ & -.053 & I8 & -364 \\
\hline .06 & 20.5 & $+\cdot 119$ & I 8 & -.065 & 15.5 & -386 \\
\hline .07 & I 8 & $+\cdot 112$ & I 5.5 & -.077 & 13.5 & -407 \\
\hline .08 & I 6 & $+\cdot 104$ & 14 & -.089 & 12 & -431 \\
\hline .09 & $I_{4}$ & +.097 & 12.5 & $-\cdot 10 I$ & I I & -.454 \\
\hline 10 & I3 & +.089 & I I & - . I I 4 & Io & -480 \\
\hline $\begin{array}{l}.15 \\
.20\end{array}$ & 9 & $\begin{array}{l}+.047 \\
+.000\end{array}$ & $\begin{array}{l}8 \\
6 \cdot 5\end{array}$ & $\begin{array}{l}-.185 \\
-.266\end{array}$ & 7 & $\begin{array}{l}-.622 \\
-.800\end{array}$ \\
\hline .25 & $\begin{array}{l}7 \\
6 \cdot 5\end{array}$ & $\begin{array}{l} \pm .000 \\
-.053\end{array}$ & $\begin{array}{l}0.5 \\
5.5\end{array}$ & -364 & $4 \cdot 7$ & -1.029 \\
\hline
\end{tabular}




\section{DISCUSSION}

Mr W. Shackleton described a series of experiments with a level in which distances derived from stadia measures were compared with actual measured values of distance. The level had internal focussing with a negative lens, and when focussed for infinity the stadia interval gave a reading correct to I per cent.

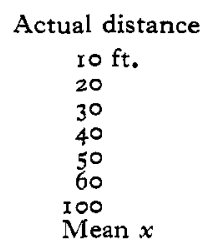

Stadia measure
$9 \cdot 78 \mathrm{ft}$.
$19 \cdot 72$
$29 \cdot 76$
$39 \cdot 70$
$49 \cdot 83$
$59 \cdot 71$
$99 \cdot 74$
775

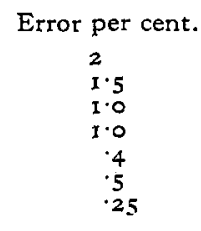

He was glad to see Major Henrici's theoretical account of the subject.

Instructor-Commander T. Y. Baker pointed out that if $\cdot 25 \mathrm{ft}$. is added to all the results given by $\mathrm{Mr}$ Shackleton the general percentage error would be decreased.

Professor Cheshire suggested that possibly better average results could be secured by making the readings correct for some mean distance rather than for infinity.

Mr R. W. Cheshire thought that Mr Shackleton's values agreed very well with those determined theoretically.

\section{(Communicated remarks)}

The approximate data of the Zeiss Level No. I, as made by Messrs T. Cooke \& Sons, of York, are as follows:

Focal length of object glass, $5 \cdot 8^{\prime \prime}$.

Focal length of negative focussing lens, $16^{\prime \prime}$.

Axial separation of object glass and focussing lens with the telescope in normal adjustment, $2 \cdot 7^{\prime \prime}$.

Distance of centre of instrument from object glass, $3 \cdot 7^{\prime \prime}$.

The centre of anallatism for near objects, say to feet or so from the instrument, is situated on the telescope axis close to the object glass. As the object focussed-on recedes from the level so also does the anallatic centre, and for very large object distances the anallatic constant tends asymptotically to a limiting value of about $4 \cdot 9^{\prime \prime}$. Curve $(a)$ indicates graphically the relation between object distances and anallatic constant, i.e. the distance of the anallatic centre from the centre of the instrument. For object distances above, say, 30 feet a fixed constant of $4.9^{\prime \prime}$ gives appreciably correct results, but for nearer objects it is obvious that the retention of the same constant of $4^{\circ} 9^{\prime \prime}$ will result in an over-estimate of the object distance. Curve $(b)$ gives the percentage error introduced at different object distances on the assumption of a fixed constant of $4^{\circ} 9^{\prime \prime}$ throughout the whole range. If no constant be added at any distance it will be equally obvious that all these object distances will be under-estimated, and the corresponding percentage errors are given by curve $(c)$. It will be noticed that, in this case, even at a distance of 
Ioo feet, the error committed is nearly one half per cent., whilst at ro feet the error will amount to about $3 \frac{1}{2}$ per cent. It may also be of interest to observe that below about to feet the error begins to diminish again.

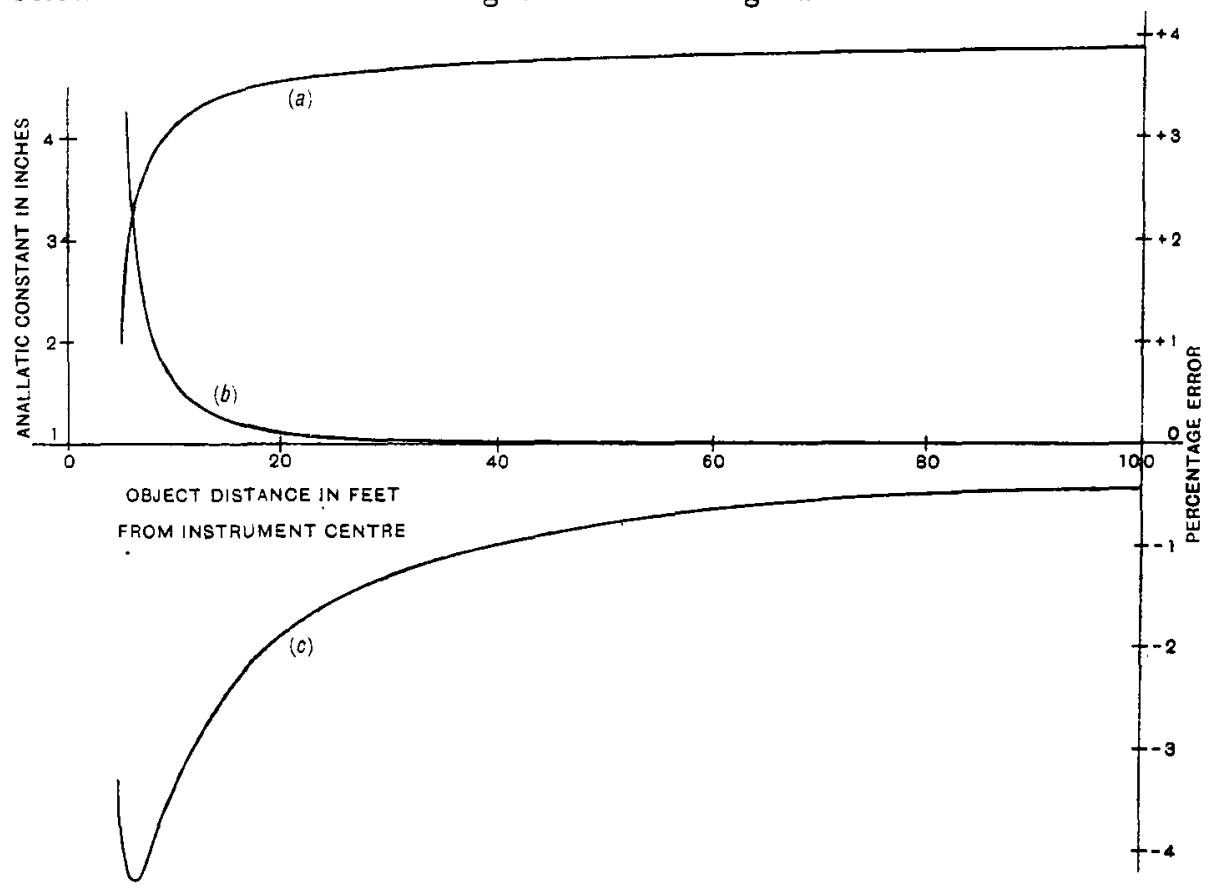

Mr T. Smith (communicated remarks) suggested a simple treatment by regarding the first principal focus of the objective and the second principal focus of the focussing lens as reference points. Instead of considering the variations in the results in absolute value he preferred treating them in proportion to the distance under measurement, and finding what the separation of the stadia lines should be and what the constant of the instrument to yield the best possible results. The quantities given in the tables did not appear to him to be comparable in the various examples, the constant $\kappa$ varying throughout the series to the extent of being. $5^{\circ}$ per cent. greater in the last case than in the first. The separation between the stadia lines, on which the accuracy obtainable in use largely depends, varies in the inverse proportion to $\kappa$ and is therefore 50 per cent. greater in the first case than in the last. ( $\kappa$ is the power when focussed for infinity.)

The author, in reply, said that Mr Shackleton's figures agreed with those in the paper as well as was to be expected; they showed that the error was practically a constant except at very short ranges.

Prof. Cheshire's suggestion did not seem practicable for the same reason that it was not practicable in the ordinary telescope. 